\title{
Analytical study of a 2-span reinforced concrete beam strengthened with fibre reinforced polymer
}

\author{
Lander VASSEUR \\ Civil Engineer \\ Magnel Laboratory for \\ Concrete Research, \\ Ghent University, \\ Ghent, BELGIUM \\ lander.vasseur@ugent.be
}

\author{
Stijn MATTHYS \\ Prof. Dr. Engineer \\ Magnel Laboratory for \\ Concrete Research, \\ Ghent University, \\ Ghent, BELGIUM \\ stijn.matthys@ugent.be
}

\author{
Luc TAERWE \\ Prof. Dr. Engineer \\ Magnel Laboratory for \\ Concrete Research, \\ Ghent University, \\ Ghent, BELGIUM \\ Luc.taerwe@ugent.be
}

\section{Summary}

The structural behaviour of reinforced concrete beams strengthened in flexure with externally bonded FRP (Fibre Reinforced Polymer) reinforcement has been extensively investigated with respect to isostatic beams. However, limited information is available on the behaviour of continuous beams, strengthened with composite reinforcement [1]. For flexural strengthening of a 2-span continuous beam the FRP can be applied above the middle support, at the two field spans or at both locations. Through an analytical study the non-linear behaviour of the beam is investigated. It is verified in which degree moment redistribution still is present when applying this strengthening technique.

Keywords: Continuous concrete beam; flexural strengthening; FRP (Fibre Reinforced Polymer), EBR (Externally Bonded Reinforcement); non-linear behaviour; moment redistribution.

\section{Introduction}

Structures may need to be strengthened for different reasons, among which a change in function, implementation of additional services or to repair damage. Different strengthening techniques exist. Often applied is externally bonded reinforcement (EBR), based on fibre reinforced polymer (FRP), the so-called FRP EBR.

FRP EBR can be applied for the strengthening of existing structures, enhancing the flexural and shear capacity, or to strengthen by means of confinement. This paper discusses flexural strengthening of a 2 span reinforced concrete beam. Herewith, CFRP (Carbon FRP) laminates are glued on the bottom or on the top or on both sides of a concrete beam. The efficiency of the FRP EBR strengthening technique is often limited by the capability to transfer stresses in the bond interface. Hereby bond failure between the laminate and the concrete may occur.

The aim of this study is to have a better insight in the behaviour of reinforced concrete structures strengthened in flexure in a multi-span situation.

\section{Analytical study of continuous beams}

\subsection{Non-linear moment-curvature diagram}

Performing an analysis of a construction according to the linear elasticity theory, a linear relationship between the moment and the curvature is obtained, namely

$$
\frac{1}{r}=\frac{M}{E I}
$$

with $1 / \mathrm{r}$ the curvature, $\mathrm{M}$ the bending moment and $\mathrm{K}=\mathrm{EI}$ the bending stiffness. This stiffness is assumed to be constant and therefore independent of the value of the bending moment. However, 
for the cross-section of a concrete beam the moment-curvature diagram is non-linear. This non-

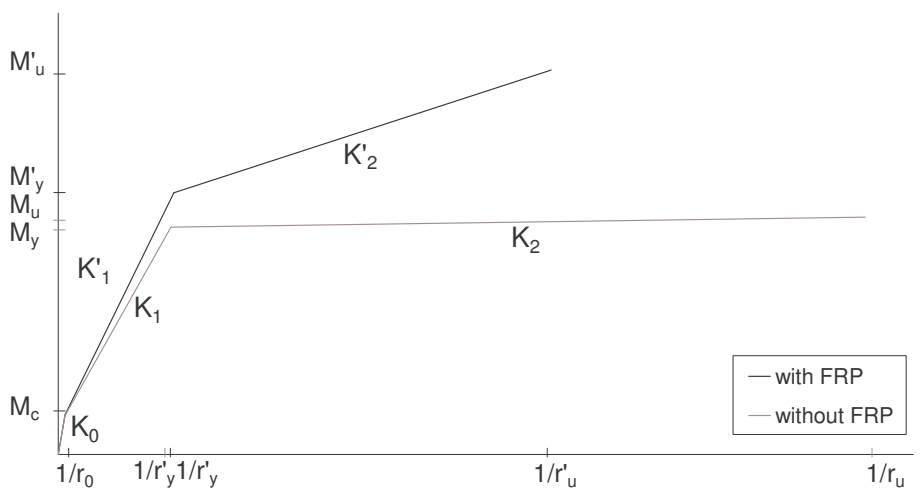

Fig. 1 Moment-curvature diagram linear character results in a variable bending stiffness, as shown in Fig. 1. Two cases are drawn in this graph, a crosssection with or without FRP. An important difference between these cases is the bending stiffness (slope of lines $\mathrm{K}_{0}, \mathrm{~K}_{1}$ and $\mathrm{K}_{2}$ ). With FRP higher values for $\mathrm{K}$ are obtained than without FRP. This different behaviour will influence the moment redistribution of a continuous beam.

If we look to Fig. 1 applied to a continuous beam, we start with the uncracked phase along the whole length of the beam, corresponding to the use of $\mathrm{K}_{0}$ as bending stiffness. By increasing the load, the beam is characterized by cracked and uncracked zones, each with the related value of bending stiffness. This change of stiffness causes a first redistribution of moments. For the yield load $\mathrm{P}_{\mathrm{y}}$, one or more cross-sections reach the yield moment $\left(\mathrm{M}_{\mathrm{y}}\right)$. In yield zones without FRP EBR, the bending stiffness $\mathrm{K}_{2}$ is so small that plastic deformations appear in the critical cross-section and in a restricted area near to it. This is the so called formation of the plastic hinge. The increasing load is mainly carried by the non plastic zones and during which the bending moment in the plastic hinge stays almost constant $\left(\mathrm{M}_{\mathrm{u}} \approx \mathrm{M}_{\mathrm{y}}\right)$ or is slowly increasing. In zones with FRP EBR, the value of the bending stiffness is higher $\left(\mathrm{K}_{2}^{\prime}\right)$. Also plastic deformations appear, but in a more limited way. The yielding zone still carries a significant part of the increasing load and the formation of the plastic hinge is restricted.

\subsection{General behaviour of continuous beams}

\subsubsection{Moment redistribution}

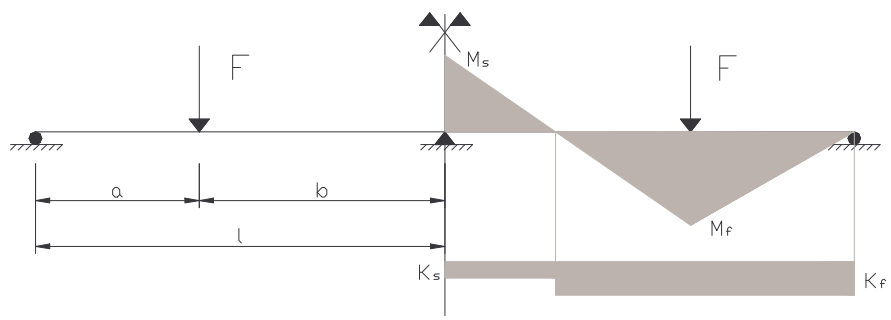

Fig. 2 Continuous beam with variable bending stiffness
Consider eg. a continuous beam with two identical spans and symmetrical loaded by two point loads (Fig. 2). Focused on one span, two zones can be defined, one zone with positive moments (above mid-support) and another with negative moments (in field span). It is assumed that in each zone the bending stiffness is constant. So the midsupport zone and the field-zone respectively have the stiffness $K_{\mathrm{s}}$ and $\mathrm{K}_{\mathrm{f}}$.

Further, we suppose:

$$
\lambda=\frac{a}{b} \quad m=\frac{M_{s}}{M_{v}} \quad k=\frac{K_{s}}{K_{v}}
$$

By considering that the angle of rotation above the mid-support equals zero, the following equation can be obtained [2]:

$$
(2+3 \lambda) m^{3}+\left(3+3 \lambda-2 k \lambda^{2}\right) m^{2}-k \lambda(3+4 \lambda) m-(1+\lambda)(1+2 \lambda) k=0
$$

With Eq. (3) the internal forces in the continuous beam can be calculated. In what follows, calculations are done for $\mathrm{a}=2 \mathrm{~m}$ and $\mathrm{b}=3 \mathrm{~m}$. Hence with $\lambda=2 / 3 \mathrm{Eq}$. (3) changes into (Fig. 3 ): 


$$
36 m^{3}+(45-8 k) m^{2}-34 k m-35 k=0
$$

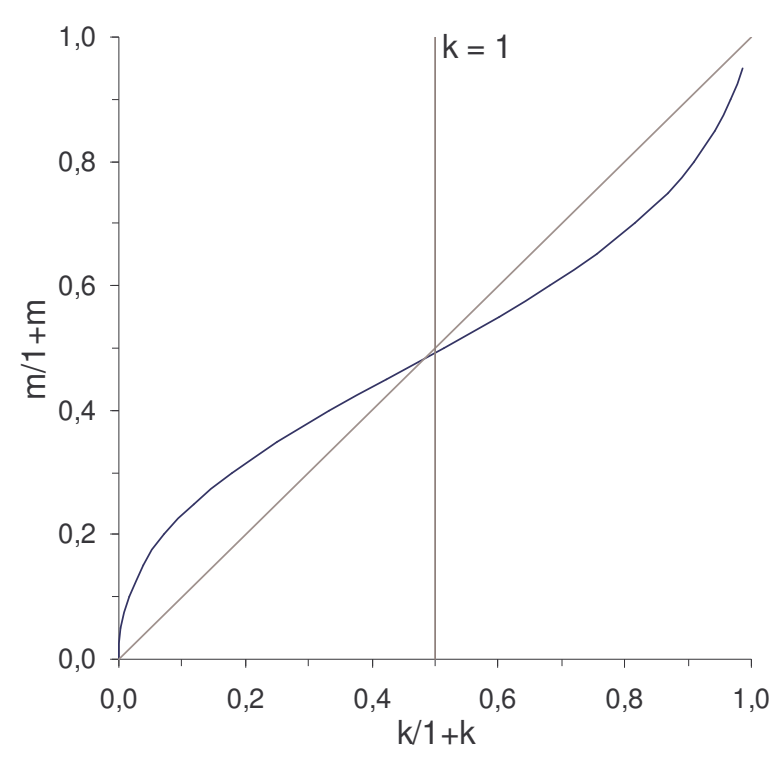

Fig. 3 The relation of the moments $m$ in function of the relation of the bending stiffnesses $k$
(4)

For loads below the cracking moment, the midsupport zone and field span zone are uncracked and the two zones nearly have the same bending stiffness. This condition correspond with $\mathrm{k}=1$. From Eq. (3) we obtain then $\mathrm{m}=0.9722=\mathrm{m}_{\mathrm{el}}$. This value of $\mathrm{m}$ corresponds to the moment distribution following the classic theory. Hereby, the relationship between acting load and internal moment is linear, as in the case of isostatic beams. By further increasing the load, the changing bending stiffnesses in different cross-sections modifies $\mathrm{k}$ thus the relation between the internal moments $\mathrm{m}$. As a result the moment distribution deviates from the classic theory to the so-called non-linear moment-redistribution.

\subsubsection{Point of contraflexure}

In continuous beams positive and negative moments are observed. The point of contraflexure, the location where the internal moment equals zero, moves with increasing load, caused by the nonlinear moment redistribution.

\subsection{Debonding mechanisms on continuous beams}

Bond failure in case of FRP EBR implies the loss of composite action between the concrete and the FRP reinforcement. This type of failure is often very sudden and brittle. According to Matthys [3] different bond failure aspects can be distinguished.

\subsubsection{Crack bridging}

The externally bonded FRP will need to bridge cracks. In regions with significant shear forces, shear or flexural cracks have a vertical (v) and a horizontal (w) displacement. The vertical displacement of the concrete causes tensile stress perpendicular to the FRP EBR, which initiates debonding of the laminate. Extending the laminates beyond the point of

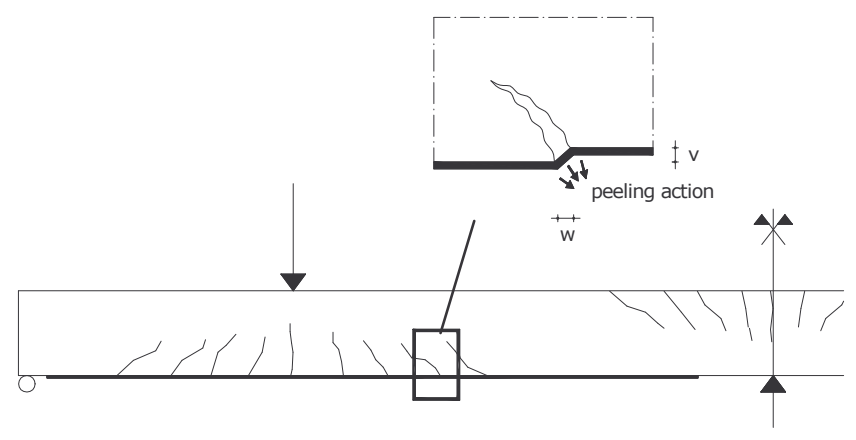

Fig. 6 Peeling-off caused at shear cracks

contraflexure has limited influence on the crack bridging, because this mechanism initiates at a location before the point of contraflexure (Fig. 6).

\subsubsection{Force transfer}

The variation of tensile force in the FRP, due to the composite action between the FRP EBR and the concrete beam initiates bond shear stresses at the interface. These shear stresses have to be smaller than the bond strength between the concrete and the FRP reinforcement. Also for this debonding mechanism the point of contraflexure has limited influence on the debonding mechanism. 


\subsubsection{Curtailment and anchorage length}

Theoretically the FRP reinforcement can be curtailed when the axial tensile force can be carried by the internal steel only. The remaining force in the FRP at this point needs to be anchored. The anchorage capacity of the interface is however limited, and hence the FRP may be extend to zones corresponding to low FRP tensile stresses. If the length of the laminate extends the location where $\mathrm{M}$ equals zero, the laminate is anchored in the compression zone and no tensile forces remain in the laminate.

\subsubsection{End shear failure}

If a shear crack appears at the plate-end, this crack may propagate as a debonding failure at the level of the internal steel reinforcement. In this case the laminate as well as a thick layer of concrete will rip off. Again the extending the FRP length beyond the point of contraflexure may avoid this debonding mechanism. By anchoring the laminate in the compressing zone, no shear cracks can appear at the plate-end.

\section{Analytical study}

For the analytical study we consider the concrete beam proposed in Fig. 2. The height of the beam equals $400 \mathrm{~mm}$ and the width $200 \mathrm{~mm}$. The characteristics of the materials are given in Table 1:

Table 1 Matarise properties

\begin{tabular}{llll}
\hline & $\mathbf{C 3 5} / \mathbf{4 5}$ & $\mathbf{S 5 0 0}$ & CFRP \\
\hline Compressive strength & $35 \mathrm{~N} / \mathrm{mm}^{2}$ & & \\
Yielding strength & & $500 \mathrm{~N} / \mathrm{mm}^{2}$ & \\
Tensile strength & $3.5 \mathrm{~N} / \mathrm{mm}^{2}$ & $550 \mathrm{~N} / \mathrm{mm}^{2}$ & $2850 \mathrm{~N} / \mathrm{mm}^{2}$ \\
Failure strain & $0.35 \%$ & $12.40 \%$ & $1.63 \%$ \\
E-modulus & $32000 \mathrm{~N} / \mathrm{mm}^{2}$ & $200000 \mathrm{~N} / \mathrm{mm}^{2}$ & $175000 \mathrm{~N} / \mathrm{mm}^{2}$ \\
\hline
\end{tabular}

As mentioned in Table 2, three different reference beams are considered, each with a specific internal reinforcement ratio $\left(\rho_{\mathrm{s}}\right)$. The first configuration has internal reinforcement as shown in Fig. 7 calculated according the linear elastic moment distribution $\left(\mathrm{m}_{\mathrm{el}}\right)$. Secondly, a beam is considered with low internal reinforcement ratio in the fields and high concentration of reinforcement above the mid-support (Fig. 8). At last, a beam is considered with a high amount of internal reinforcement in

Table 2 Different used configurations of internal steel reinforcement $\left(\rho_{s}\right)$

\begin{tabular}{lll}
\hline Configuration & $\begin{array}{l}\text { field } \\
\left(\boldsymbol{\rho}_{\mathrm{sf}}\right)\end{array}$ & $\begin{array}{l}\text { mid-support } \\
\left(\boldsymbol{\rho}_{\mathrm{ss}}\right)\end{array}$ \\
\hline 1 & $0.71 \%$ & $0.71 \%$ \\
2 & $0.48 \%$ & $1.30 \%$ \\
3 & $0.91 \%$ & $0.29 \%$ \\
\hline
\end{tabular}
the fields and a low reinforcement ratio at the mid-support (Fig. 9).

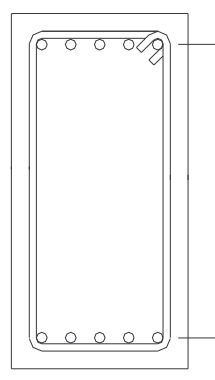

$2 \mathrm{x}$ diam 12 (cont.) 3 x diam 12 (add. at mid support)

2 x diam 12 (cont.) 3 x diam 12 (add. at fields)

Fig. 7 Configuration 1 of internal steel

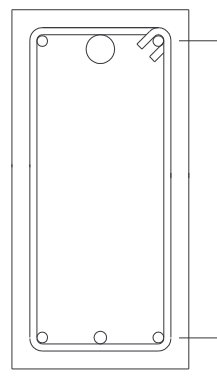

2 x diam 12 (cont.) $1 \mathrm{x}$ diam 32 (add. at mid support)

$2 \mathrm{x}$ diam 12 (cont.) $1 \mathrm{x}$ diam 14 (add. at fields)

Fig. 8 Configuration 2 of internal steel

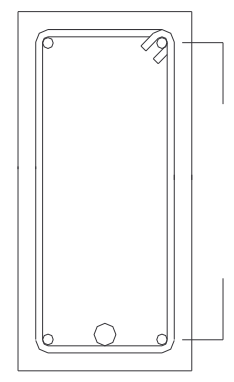

2 x diam 12 (cont.)

$2 \mathrm{x}$ diam 12 (cont.) $1 \mathrm{x}$ diam 25 (add. at fields)

Fig. 9 Configuration 1 of internal steel

Four different cases of external reinforcement ratio $\left(\rho_{\mathrm{f}}\right)$ are investigated for each reference beam 
(Table 3): case A, the 2 span beam without external reinforcement, case B, the beam with FRP EBR above the middle support and in the field spans, case C, the beam with FRP EBR only in the field spans and case D the beam with FRP EBR above the middle support. The FRP laminates have following dimensions: $t_{f}=1,2 \mathrm{~mm}$ and $b_{f}=100 \mathrm{~mm}$. The length of the bottom laminate is $3750 \mathrm{~mm}$, the length of the top laminate is $5000 \mathrm{~mm}$ (Fig. 10).

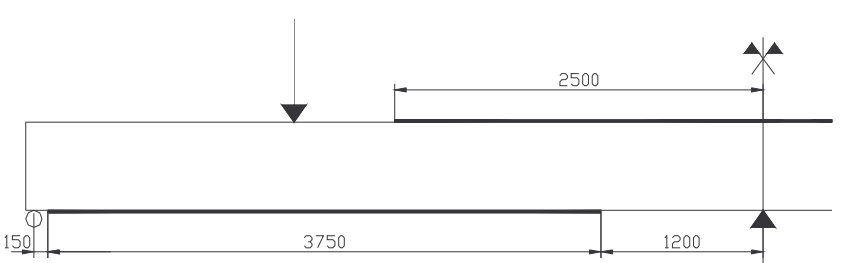

Fig. 10 Dimension of FRP-laminates used in analytical study

Table 3 Different used configurations of internal steel reinforcement $\left(\rho_{f}\right)$

\begin{tabular}{lll}
\hline Case & $\begin{array}{l}\text { field } \\
\left(\rho_{\mathrm{ff}}\right)\end{array}$ & $\begin{array}{l}\text { mid- } \\
\text { support }\end{array}$ \\
\hline $\mathrm{A}$ & - & - \\
$\mathrm{B}$ & $0.17 \%$ & $0.17 \%$ \\
$\mathrm{C}$ & $0.17 \%$ & -
\end{tabular}

$\mathrm{D}$

$0.17 \%$

\section{Results of analytical study}

The results of the strengthening effect and failure aspect are summarized in table 4.

The moment redistribution is illustrated in Figs. 11-22. These graphs give the field span moment $\mathrm{M}_{\mathrm{v}}$ and the mid-support moment $\mathrm{M}_{\mathrm{S}}$ at the critical section (where the moment is maximum), as a function of the acting point load P. In each graph a linear curve and a non-linear curve is observed. The linear curve is the moment distribution calculated by the classic theory. Hereby, the relationship between the acting load and the internal moment is linear. The non-linear curve is the moment distribution calculated by the non-linear theory.

Table 4. Results of analytical study

\begin{tabular}{|c|c|c|c|c|}
\hline Configuration & $\begin{array}{l}\text { Ult. load (excl. } \\
\text { debonding) } \\
{[\mathrm{kN}]}\end{array}$ & $\begin{array}{l}\text { Ult. load (incl. } \\
\text { debonding) } \\
{[\mathrm{kN}]}\end{array}$ & $\begin{array}{l}\text { Strengthening } \\
\text { ratio }\end{array}$ & Failure aspect \\
\hline $1-\mathrm{A}$ (ref.) & 110.9 & 110.9 & 1.00 & Concrete crushing \\
\hline $1-\mathrm{B}$ & 223.8 & 156.8 & 1.41 & Concrete rip-off \\
\hline $1-\mathrm{C}$ & 165.7 & 143.2 & 1.29 & Concrete rip-off \\
\hline $1-\mathrm{D}$ & 142.2 & 142.2 & 1.28 & Concrete Crushing \\
\hline $2-\mathrm{A}$ (ref.) & 108.1 & 108.1 & 1.00 & Concrete Crushing \\
\hline $2-B$ & 209.5 & 152.6 & 1.41 & Crack bridging \\
\hline $2-\mathrm{C}$ & 178.8 & 147.8 & 1.36 & Concrete rip-off \\
\hline $2-\mathrm{D}$ & 128.5 & 128.5 & 1.18 & Concrete Crushing \\
\hline $3-\mathrm{A}$ (ref.) & 106.9 & 106.9 & 1.00 & Concrete Crushing \\
\hline $3-\mathrm{B}$ & 220.3 & 143.8 & 1.34 & Crack bridging \\
\hline $3-C$ & 141.0 & 112.3 & 1.05 & Concrete rip-off \\
\hline $3-D$ & 148.3 & 130.4 & 1.22 & Crack bridging \\
\hline
\end{tabular}

\subsection{First configuration: $\rho_{\mathrm{sf}}=\mathbf{0 . 7 1} \%$ and $\rho_{\mathrm{ss}}=0.71 \%$}

In case A and B (Fig. 11 and 12) the moment distribution is quasi similar to the linear curve calculated by the classic theory, no plastic hinges are observed. Field span and mid-support start to yield at nearly the same moment. In case B debonding is obtained at $156.8 \mathrm{kN}$ (dashed line) by concrete rip-off at the bottom laminate at one of the extreme supports. In case C, by using FRP EBR 
only in the fields, a plastic hinge is formed at the mid-support (vertical line in Fig. 13 after yielding of reinforcement at the support). Although the field starts to yield shortly afterwards, almost all additional loads are taken by this field, by means of the FRP. Again concrete rip-off appears at the same location, in case C at $143.2 \mathrm{kN}$. Case D (Fig. 14) is similar to case C, whereby the plastic hinge is formed in both fields and additional loads are taken by the mid-support (debonding is not governing in case D).

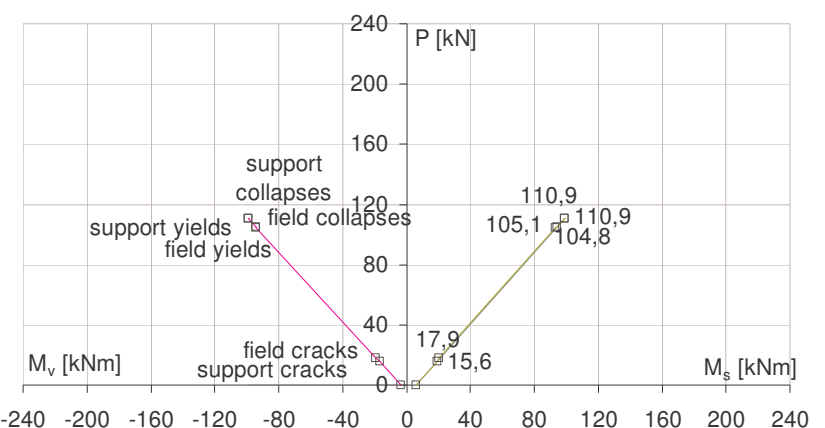

Fig. 11 Case A: moment redistribution without strengthening

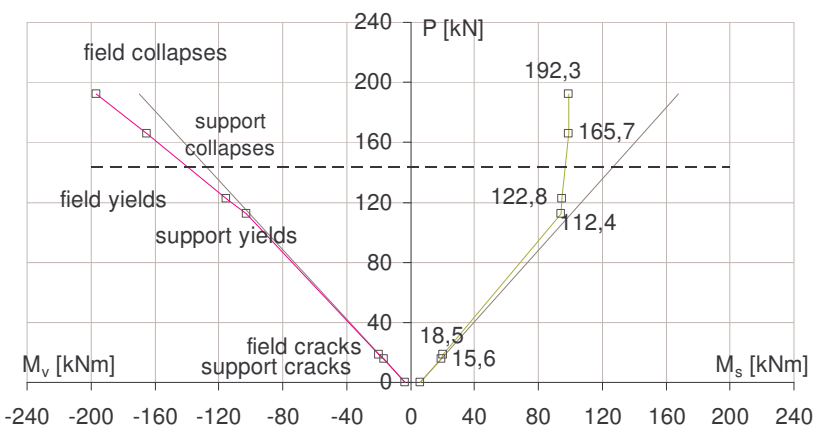

Fig. 13 Case C: moment redistribution with FRP EBR at fields

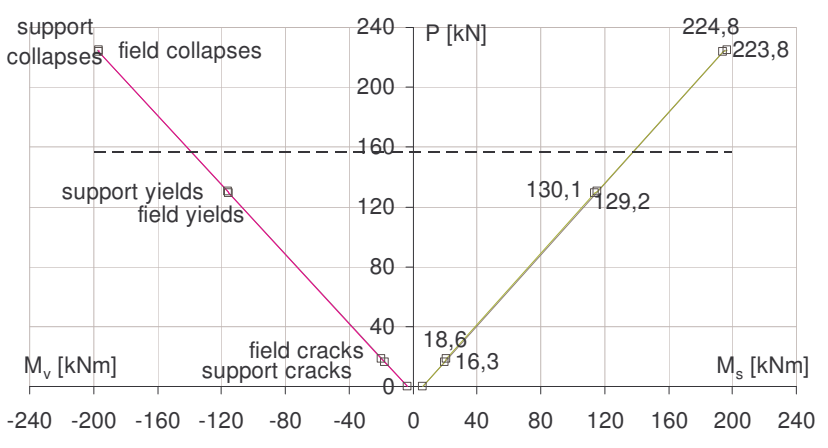

Fig. 12 Case B: moment redistribution with FRP EBR at fields and above the mid-support

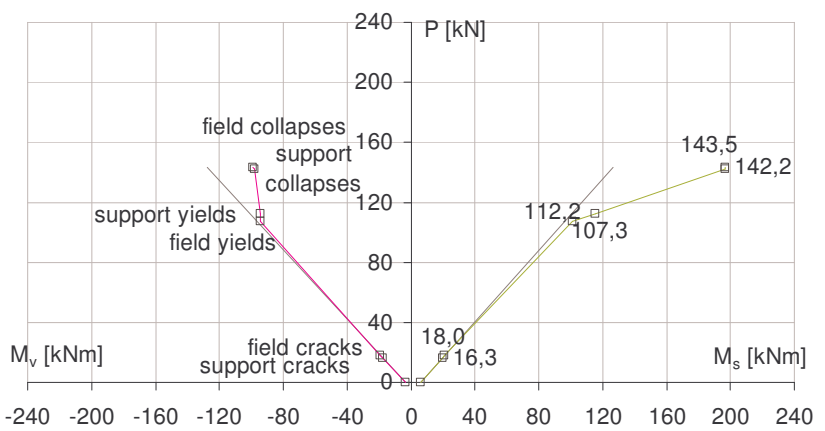

Fig. 14 Case D: moment redistribution with FRP EBR above the mid-support

\subsection{Second configuration: $\rho_{\mathrm{sf}}=\mathbf{0 . 4 8} \%$ and $\rho_{\mathrm{ss}}=1.30 \%$}

In all cases the field yields first. The reference beam (case A, Fig. 15) forms plastic hinges in the field spans from the moment the field spans start to yield. All additional loads are taken up by the mid-support. By using FRP EBR in both locations (case B, Fig. 16) the moment distribution correlates more with the linear distribution, according to the classic theory. In this case additional load is taken by the FRP at both the field span and mid-support. At $152.6 \mathrm{kN}$ debonding is obtained by crack bridging at the bottom laminate near to the mid-support. In case $\mathrm{C}$ (strengthened in the field spans, Fig. 17) it is observed that the plastic hinge is formed at the mid-support in stead of the field spans, due to strengthening of the latter. Although the strengthened fields still start to yield first, the FRP allows the field spans to continue resisting the additional load. At increasing load when the support starts to yield, a plastic hinge is formed at this mid-support. Concrete rip-off is observed at $147.8 \mathrm{kN}$ at the bottom laminate. In case D (Fig. 18) the plastic hinge formation is similar to case A but extends to a higher load level due to the additional moment redistribution at the strengthened mid-support zone (debonding is not governing in this case). 


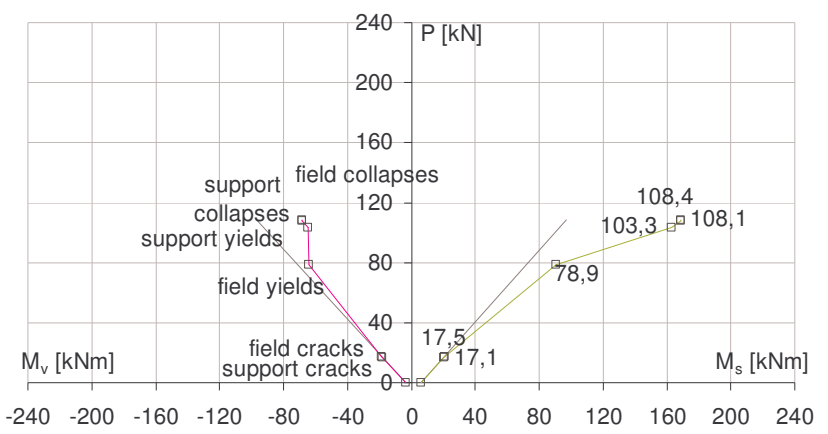

Fig. 15 Case A: moment redistribution without strengthening

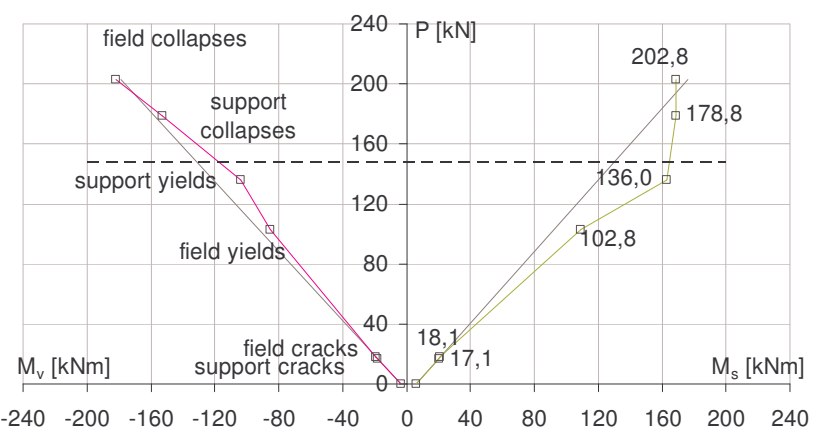

Fig. 17 Case C: moment redistribution with FRP EBR at fields

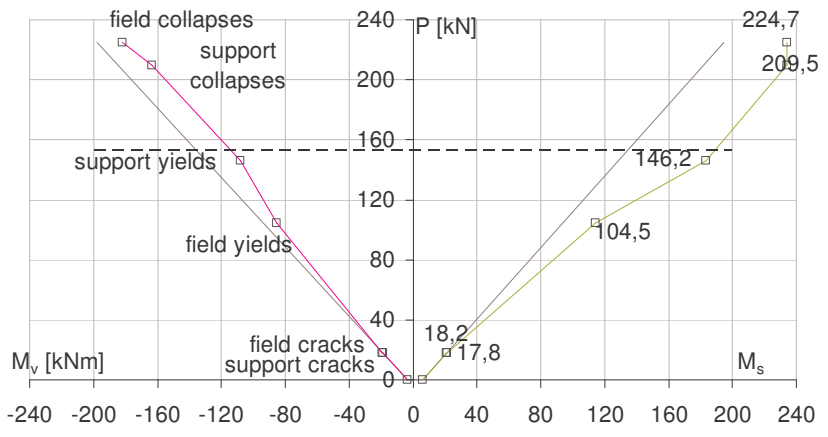

Fig. 16 Case B: moment redistribution with FRP EBR at fields and above the mid-support

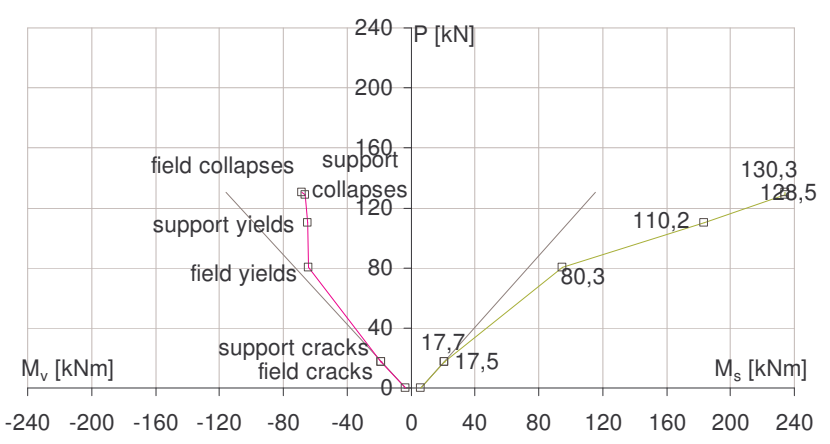

Fig. 18 Case D: moment redistribution with FRP EBR above the mid-support

\subsection{Third configuration: $\rho_{\mathrm{sf}}=\mathbf{0 . 9 1} \%$ and $\rho_{\mathrm{ss}}=\mathbf{0 . 2 9 \%}$}

In all cases the mid support yields first. The reference beam (case A, Fig. 19) is characterized by formation of a plastic hinge at the mid-support, from the moment the mid-support yields. Additional load is taken by the field spans. By using FRP EBR in both locations (case B, Fig. 20) the same tendency is noticed as in the second configuration, namely the moment distribution correlates more with the linear distribution. As debonding mechanism we have crack bridging at $143.8 \mathrm{kN}$ at the top laminate. In case $\mathrm{C}$ (strengthened in the field spans, Fig. 21) the plastic hinge formation is similar to case A but extends to a higher load level due to the additional moment redistribution at the strengthened field zone. Concrete rip-off appears at $112.3 \mathrm{kN}$ at the bottom-laminate, near to the mid-support. Because of the moment redistribution, whereby $\mathbf{M}_{\mathrm{s}}$ remains limited, the point of contraflexure moves near to the mid-support, so the anchorage length of the bottem laminate is no longer in the compressive zone and concrete rip-off is not avoided. In case D (Fig. 22) it is observed, similar to in case $\mathrm{C}$ of the second configuration, that the plastic hinge has changed from location, due to strengthening of the mid-support. Although the strengthened mid-support still starts to yield first, the FRP allows the mid-support to continue resisting the additional load. At increasing load when the field spans start to yield, plastic hinges are formed in the fields. Debonding by crack bridging is observed at the top laminate at $130.4 \mathrm{kN}$.

\section{Conclusions}

For unstrengthened continuous beams a considerable moment redistribution can be observed, especially after plastic hinge formation. The latter occurs after reaching the yield moment in the critical cross-section (where the moment is maximum). Almost no moment redistribution is however observed if the yield moment is reached at the same time in both the field spans and the mid-support. 


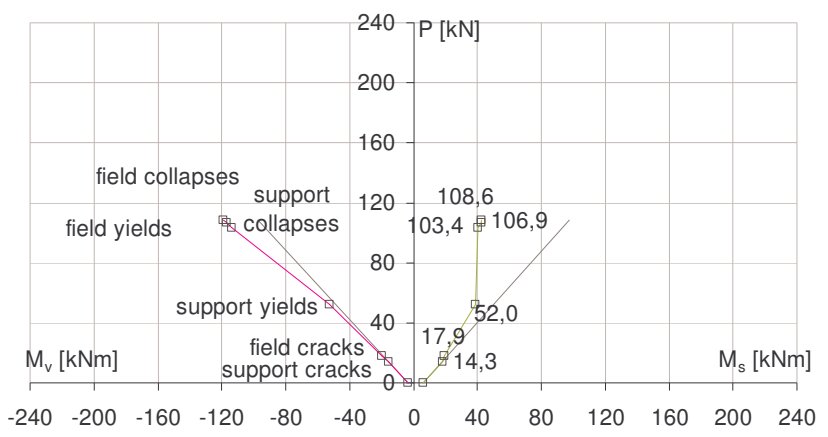

Fig. 19 Case A: moment redistribution without strengthening

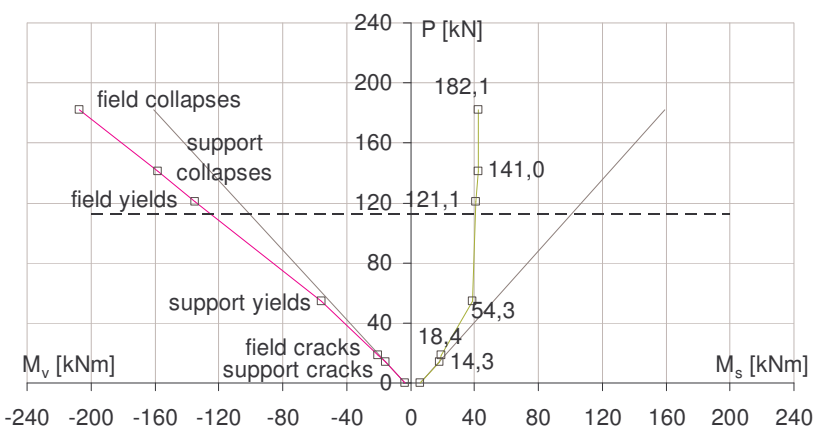

Fig. 21 Case C: moment redistribution with FRP EBR at fields

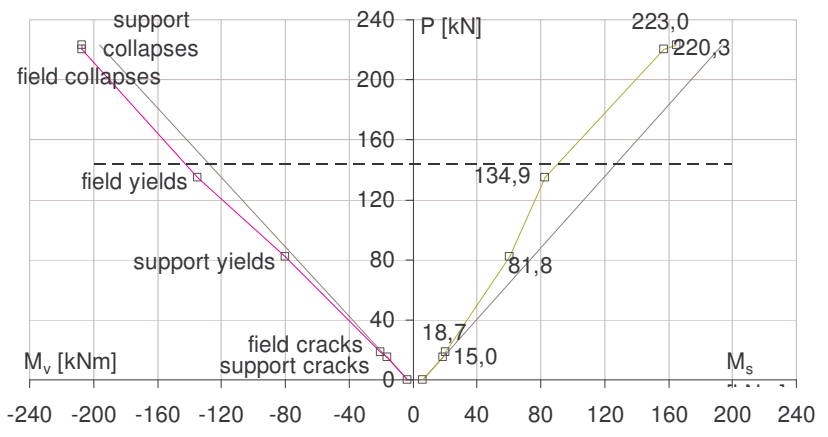

Fig. 20 Case B: moment redistribution with FRP EBR at fields and above the mid-support

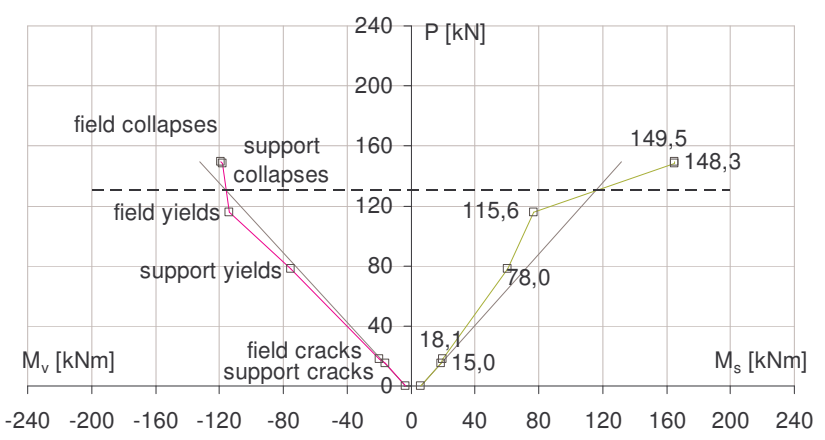

Fig. 22 Case D: moment redistribution with FRP EBR above the mid-support

In the case of FRP EBR strengthened continuous beams the observed behaviour largely depends on the amount of internal steel reinforcement in the field span and mid-support and the strengthening configuration. After reaching the yield moment, the FRP strengthened cross-section is still able to contribute in carrying the additional load. Hence, such FRP strengthened cross-sections restrict the formation of a plastic hinge at that location (and the related moment redistribution), but allow to transfer plastic hinge formation to unstrengthened cross-sections with high internal steel reinforcement ratio by strengthening the sections with low internal steel reinforcement ratio. Strengthening of the section with high internal steel reinforcement ratio has a limited strengthening effect and largely depends on the rotation capacity of the unstrengthened section with low steel reinforcement. Overall strengthening (both the field spans and the mid-support) typically results in restriction of plastic hinge formation in both the field spans and mid-support zones. This strengthening configuration is characterized by almost no moment redistribution, and whereas the strengthening effect mainly relates to the amounts of FRP EBR.

\section{References}

[1] EL-REFAIE S. A., ASHOUR A.F. and GARRITY S.W., "Sagging and Hogging strengthening of continuous reinforced concrete beams using carbon-fiber-reinforced polymer sheets", $A C I$ structural journal, July-August 2003, pp. 446-453

[2] TAERWE L., "Doorlopende liggers van gewapend beton", Annales des traveaux Publics de Belgique, No. 5, 1981, pp.423-441

[3] Matthys S. (2000): "Structural behaviour and design of concrete members strengthened with externally bonded FRP reinforcement" Doctoral thesis, Ghent University, 2000, 345p. 